\title{
Studies on the Purification of
}

\section{Antihemophilic Factor (Factor VIII)}

\author{
II. SEPARATION OF PARTIALLY PURIFIED \\ ANTIHEMOPHILIC FACTOR BY GEL FILTRATION OF PLASMA
}

\author{
Oscar D. Ratnoff, Lawrence Kass, and P. Dieter Lang \\ From the Department of Medicine, Case Western Reserve University School of \\ Medicine, and University Hospitals of Cleveland, Cleveland, Ohio 44106
}

\begin{abstract}
A в S T R A C T A high degree of purification of antihemophilic factor was achieved by filtration of chylomicronpoor human plasma through columns of agarose. The final product contained, on the average, 67 units of antihemophilic activity per $\mathrm{mg}$ of protein, and was 3360 -fold purified compared with the filtered plasma. The molecular weight of antihemophilic factor appeared to be at least two million. Preparations separated by gel filtration were contaminated with appreciable amounts of plasma thromboplastin antecedent (PTA), and traces of Christmas factor and Hageman factor, but no detectable fibrinogen was present. Similar fractions of plasma prepared from the blood of patients with classic hemophilia, von Willebrand's disease, or a circulating anticoagulant directed against antihemophilic factor contained, on the average, somewhat less protein than normal plasma; whether this difference was significant is not yet known. The purified fractions were partially stabilized by the addition of $1 \%$ gelatin. Adaptation of the technique of gel filtration to purification of antihemophilic factor for clinical use remains to be explored.
\end{abstract}

\section{INTRODUCTION}

Many methods have been proposed for the partial purification of antihemophilic factor (factor VIII) from human plasma. Recently, we described a technique in which this clot-promoting agent was separated from cryoprecipitates of normal plasma by precipitation with concanavalin A, a globulin derived from jack beans (1). The purification achieved was approximately $350-$ to

Dr. Ratnoff is a Career Investigator of the American Heart Association.

Received for publication 18 November 1968 and in revised form 31 December 1968.
800 -fold compared with the plasma from which the fractions were separated. Its precipitation by concanavalin $\mathrm{A}$ implied that antihemophilic factor is a glycoprotein, and its behavior on ultracentrifugation, gel filtration, and disc electrophoresis suggested that its mol wt is greater than two million. Whether the great molecular size of antihemophilic factor is due to aggregation of smaller units during its separation from plasma in the cold could not be determined.

The present report outlines a much simpler method for separating small amounts of antihemophilic factor by utilizing agarose gel filtration, a step previously used by Johnson (2), Hershgold (3) and their associates. The specific activity of the purest fractions, prepared from chylomicron-poor human plasma, averaged 67 units/mg of protein and represented purification, compared to the plasmas from which they were separated, as high as 6300 -fold. Evidence was obtained that the molecular weight of antihemophilic factor, as it exists in freshly drawn plasma, is indeed probably greater than two million.

\section{METHODS}

Citrated plasma was prepared from venous blood to which $1 / 9$ volume of sodium citrate buffer $(\mathrm{pH} 5.0,0.13 \mathrm{M}$ with respect to citrate) had been added. The blood was obtained from normal individuals, from patients with classic hemophilia (factor VIII deficiency) or von Willebrand's disease, and from a patient with a circulating anticoagulant directed against antihemophilic factor, first noted post partum. In some experiments, normal donors exercised for $10 \mathrm{~min}$ before venepuncture to increase the concentration of antihemophilic factor in blood.

Casual samples of plasma were prepared, without attention to the subjects' diet, by drawing blood through disposable No. 18 gauge needles into polypropylene syringes (Monocote, Roehr Products Co., Inc., Deland, Fla.) moistened with silicone oil [Silicone Fluid-96 (200) General Electric Com- 
pany, Waterford, N. Y.]. The blood was transferred to cellulose nitrate (Lusteroid) tubes coated with silicone (Dri-Film SC-87, General Electric Company) fortified with silicone oil. In some experiments centrifugation was carried out at $3500 \mathrm{rpm}$ for $15 \mathrm{~min}$ at $2^{\circ} \mathrm{C}$. In others, the citrate buffer was prewarmed to $37^{\circ} \mathrm{C}$, and centrifugation was carried out at room temperature for $10 \mathrm{~min}$ in warmed steel centrifuge cups filled with water heated to $37^{\circ} \mathrm{C}$. The supernatant plasmas were transferred to silicone-coated Lusteroid tubes and used immediately.

Chylomicron-rich plasma from the blood of subjects who had ingested a fatty meal of their own choosing within $3 \mathrm{hr}$ before venepuncture, was prepared with uncoated syringes and uncoated polypropylene centrifuge cups to avoid admixture of silicone oil and the plasma. The plasma was separated by centrifugation at $3500 \mathrm{rpm}$ for $15 \mathrm{~min}$ at $2{ }^{\circ} \mathrm{C}$, transferred to uoncoated polypropylene tubes, and used immediately.

Chylomicron-poor plasma from the blood of subjects who had ingested no fat other than that in bread or dry cereal since the preceding evening meal, was prepared with uncoated syringes and centrifuge tubes. The plasma was separated by centrifugation at $16,000 \mathrm{rpm}$ for $10 \mathrm{~min}$ at $2^{\circ} \mathrm{C}$, transferred (with care to avoid the uppermost layer of plasma) to uncoated polypropylene tubes, and used immediately.

Cryoprecipitates of normal human plasma, prepared essentially by the method of Pool and her associates (4), were donated by the Cleveland Biologicals Donor Service, Cleveland, Ohio. The cryoprecipitates were thawed at room temperature and suspended in a minimal volume of buffer, to a final volume of $7-11 \mathrm{ml}$.

Sepharose $4 B$ (Pharmacia Fine Chemicals, Inc., Uppsala, Sweden), a $4 \%$ spherical agarose gel with a particle size of $40-190 \mu$ in the swollen state, was suspended in buffer. Columns of the gel, $0.9 \mathrm{~cm}$ in diameter and 33 or $56 \mathrm{~cm}$ in height, or $2.5 \mathrm{~cm}$ in diameter and approximately $36 \mathrm{~cm}$ in height, were supported by nylon netting. The columns were washed at 4 or $37^{\circ} \mathrm{C}$ with a constant-drip of buffer. The recovery of antihemophilic factor from a given lot of Sepharose 4B was greatly improved by pretreating the column by filtration of plasma.

Gel filtration through columns $0.9 \mathrm{~cm}$ in diameter was performed at 4 or $37^{\circ} \mathrm{C}$ by applying $2.5 \mathrm{ml}$ of fresh plasma and eluting with buffer at a pressure of 50 to $60 \mathrm{~cm}$ above the outlet of the column. The effluent was collected in $1.0 \mathrm{ml}$ aliquots and assayed immediately for antihemophilic activity and total protein (1). Gel filtration through columns 2.5 $\times 36 \mathrm{~cm}$ in size was carried out at $4^{\circ} \mathrm{C}$ by applying $5 \mathrm{ml}$ of fresh plasma or the entire volume of a cryoprecipitate and eluting with buffer at a pressure of 80 to $120 \mathrm{~cm}$ above the outlet of the column; the effluent was collected in $2.0-\mathrm{ml}$ aliquots. The void volume was determined by filtration of Blue Dextran 2000 (Pharmacia); other markers used were porcine thyroglobulin (Sigma Chemical Co., St. Louis, Mo., mol wt 670,000) and bovine gamma globulin (Armour Pharmaceutical Co., Kankakee, Ill., mol wt 160,000) (1).

Ultracentrifugation was conducted as described before (1), with linear gradients of $5-20 \%$ sucrose in $0.15 \mathrm{M}$ Tris (hydroxymethyl) amino methane, and porcine thyroglobulin (19S) and subribosomal particles (40S and 58S) as markers. $0.2 \mathrm{ml}$ of either normal plasma, undiluted or diluted eightfold with $0.15 \mathrm{M}$ sodium chloride solution, or antihemophilic factor-rich eluates, obtained by gel filtration, was applied to the surface of the gradients, and the samples were centrifuged at $35,000 \mathrm{rpm}$ for $3 \mathrm{hr}$ at $0^{\circ} \mathrm{C}$. Fractions, each about $0.22 \mathrm{ml}$ in volume, were collected by puncturing the bottom of the centrifuge tubes and assayed for antihemophilic factor; the plasma fractions were also assayed for protein.

Assays for the presence of clotting factors and plasminogen were conducted as described previously (1). The concentration of antihemophilic factor was compared to that of a standardized, lyophilized pool of human plasma (provided through the kindness of Dr. David L. Aronson, the Division of Biologics Standards, National Institutes of Health) which, when reconstituted, contained 1.3 units of antihemophilic factor $/ \mathrm{ml}, 1$ unit of antihemophilic factor being that amount present in $1 \mathrm{ml}$ of pooled normal human plasma (5). The presence of fibrinogen in gel filtrates was also tested by Ouchterlony gel diffusion $(6,7)$ with rabbit anti-human fibrinogen antiserum (Hyland Laboratories, Los Angeles, Calif.). This technique permitted detection of fibrinogen in normal plasma, diluted $1: 100$, but not in plasma diluted $1: 200$.

To establish the specific presence of antihemophilic factor in gel filtrates, aliquots were incubated with appropriate amounts of plasma from a patient known to have a potent circulating anticoagulant directed against antihemophilic factor, and assayed as described earlier (1).

The presence of lipids in gel filtrates was tested by qualitative thin-layer chromatography. Chloroform-methanol $2: 1$ extracts of $1 \mathrm{ml}$ aliquots of the filtrates were applied in narrow bands to plates coated with Silica Gel $\mathrm{H}-\mathrm{HR}$ (E. Merck A. G., Darmstadt, Germany). The technique of development by multiple solvents was employed, the first system being acetone-benzene $20: 80$, and the second isooctane-ethyl acetate $100: 1$. The developed plates were sprayed with Rhodamine $6 \mathrm{G}$, and the lipids made visible under ultraviolet light. Standards of known composition, run concomitantly, were used for identification. The proportions of the various lipids present in one specimen were estimated by the size and the intensity of the bands. Additionally, the presence of $\beta$-lipoprotein in gel filtrates was tested by Ouchterlony agar gel immunodiffusion $(6,7)$ with goat anti-human $\beta$-lipoprotein antiserum (Miles-Yeda, Miles Laboratories, Inc., Elkhart, Ind.).

To stabilize antihemophilic factor, fractions rich in this factor were mixed with an equal volume of glycerol (USP) or with $1 / 6$ volume of $0.6 \mathrm{M}$ epsilon aminocaproic acid (Mann Research Labs., Inc., New York), 0.6 M glycine (Fisher Scientific Company, Fair Lawn, N. J.), 6\% bovine albumin in buffer (fraction V, Armour Pharmaceutical Company), or $0.75-6 \%$ gelatin (Bactogelatin, Difco Laboratories, Detroit, Mich.). The gelatin was dissolved in buffer with gentle heating. The mixtures were quick-frozen in polypropylene tubes immersed in an ethanol-dry ice mixture and stored at $-20^{\circ} \mathrm{C}$. We prepared lyophilized fractions in a Virtis No. 10MRSA lyophilizer (Virtis Company, Gardiner, N. Y.) after quick-freezing the samples in glass vials, maintaining the freezing plate at cold temperatures.

Unless otherwise noted, buffer refers to barbital-saline buffer $(0.025 \mathrm{M}$ barbital-sodium barbital, $0.125 \mathrm{M}$ sodium chloride, $\mathrm{pH}$ 7.5) (1). Protein determinations were performed by the method of Lowry, Rosebrough, Farr, and Randall (8), modified by using equal volumes of the solution to be tested and double-strength reagent $\mathrm{C}$. This allowed the measurement of protein at concentrations as low as about $3 \mu \mathrm{g} / \mathrm{ml}$. Centrifugation at $3500 \mathrm{rpm}(2750 \mathrm{~g})$ at $2^{\circ} \mathrm{C}$ was performed in an International PR2 refrigerated centrifuge, and at $37^{\circ} \mathrm{C}$, in an International model UV centrifuge. Centrifugation at $16,000 \mathrm{rpm}(31,000 \mathrm{~g})$ was in a Sorvall $\mathrm{RC} 2$ refrigerated centrifuge at $2^{\circ} \mathrm{C}$. 


\section{RESULTS}

Filtration of casual samples of normal plasma at $4^{\circ} \mathrm{C}$. When normal plasma was filtered through agarose at $4^{\circ} \mathrm{C}$, antihemophilic activity appeared in fractions close to the void volume of the columns, whether these were $0.9 \times 33 \mathrm{~cm}$ or $2.5 \times 36 \mathrm{~cm}$ in size. Antihemophilic activity was not detected at any other point in the elution pattern. The peak of antihemophilic activity coincided with a small protein peak, which emerged from the columns at a point preceding that at which porcine thyroglobulin was eluted. Aliquots with the highest antihemophilic activity were tested for the presence of other clotting factors. None contained coagulable protein or plasminogen, as measured by the techniques described, but these techniques were not sensitive to concentrations of fibrinogen below about $20 \mu \mathrm{g} / \mathrm{ml}$. PTA (factor XI) was present at concentrations as high as $5 \%$ that of the filtered plasma, and at least some of this appeared to be activated. Traces $(<1 \%)$ of Hageman factor (factor XII) and proaccelerin (factor V) were also detected. $\beta$-Lipoprotein could not be demonstrated immunologically. In 12 experiments, the purification achieved by fractionation of casual samples of plasma was 320- to 2000 -fold, averaging 1500 -fold, and the specific activity of the antihemophilic factor in the purest fractions of each experiment ranged from 2.9 to 47 units per $\mathrm{mg}$ of protein, averaging 18 units $/ \mathrm{mg}$. From 20 to $66 \%$ of the antihemophilic factor of the filtered plasma was recovered in a volume of 3-20 ml, the average recovery being about $40 \%$; the purification of such pools was slightly less than that in the tube with highest specific activity. Similar results were obtained by filtering plasma through columns of agarose $0.9 \times 56 \mathrm{~cm}$ in size at $4^{\circ} \mathrm{C}$.

Filtration of chylomicron-rich and chylomicron-poor samples of normal plasma at $4^{\circ} \mathrm{C}$. A chance observation suggested that the purity of antihemophilic factor was a function of the chylomicron content of the plasma tested. Blood was drawn from three normal subjects within $3 \mathrm{hr}$ after they had ingested a fatty breakfast, and the plasma separated at relatively low centrifugal force $(2750 \mathrm{~g})$. The plasma was then applied at $4^{\circ} \mathrm{C}$ to agarose columns $2.5 \times 36 \mathrm{~cm}$ in size. Antihemophilic factor appeared at approximately the void volume; the tubes containing the highest activity were grossly turbid. Analysis of the lipid content of these tubes demonstrated triglycerides and phospholipids in approximately equal proportions. In two of the three individuals traces of free cholesterol were present. Highly nonpolar compounds, possibly hydrocarbons or carotenoids, were noted in all tubes, but these were also present in buffer which had been filtered through agarose. The technique used did not allow determination of the concentrations of the various lipids. The antihemophilic activity of fractions of highest purity varied from 10 to 22.5 units $/ \mathrm{mg}$ of protein; purification was approximately 1000 - to 1600 -fold.

We repeated the experiment 15 times, using plasma obtained from donors who had avoided the ingestion of fats (Fig. 1) and separating the plasma at relative high centrifugal force $(31,000 \mathrm{~g})$. Now the void volume contained antihemophilic activity of much greater purity. The specific activity varied from 11 to 228 units/mg of protein, averaging 67 units $/ \mathrm{mg}$, and the degree of purification achieved was 350- to 6300 -fold, averaging 3360 fold. After $5 \mathrm{ml}$ of plasma was applied to the column, about $50 \%$ of the total activity could be recovered in a volume of 8-14 $\mathrm{ml}$, but the purity achieved by pooling active fractions was slightly less than that of the tubes with the greatest specific activity. The purest fractions contained PTA at a concentration about $2 \%$ that of the plasma that was filtered, as well as traces $(<0.1 \%)$ of Christmas factor (factor IX) and Hageman factor, but none of the other factors tested was detected. Lipid analysis of filtrates of three chylomicron-poor plasmas showed phospholipids as the dominant components with smaller amounts of triglycerides. The presence of highly nonpolar compounds was also observed. The total lipid content of these filtrates seemed grossly smaller than those obtained from chylomicron-rich plasmas.

Filtration of normal plasma at $37^{\circ} \mathrm{C}$. The experiments described do not tell us whether antihemophilic factor, as it exists in plasma, is a macromolecule, or whether it aggregates when exposed to the cold temperatures used during centrifugation and filtration. To test this, plasma was prepared by centrifuging fresh citrated blood at or near $37^{\circ} \mathrm{C}$, and then filtered through columns of agarose, $0.9 \times 56 \mathrm{~cm}$, at $37^{\circ} \mathrm{C}$. In three such experiments, antihemophilic factor activity appeared at the void volume; the filtrates contained 12.5-16 units of antihemophilic factor $/ \mathrm{mg}$ of protein. These experiments are evidence that the large molecular size of antihemophilic factor is not an artefact induced by exposure to cold.

The identity of antihemophilic factor. The clot-promoting activity of the fractions of plasma filtered with the void volume was attributed to their content of antihemophilic factor because they corrected the coagulative defect of hemophilic plasma. To corroborate this interpretation, fraction rich in antihemophilic factor were incubated with plasma containing a circulating anticoagulant directed against this substance. The antihemophilic activity of the filtered fractions was inactivated by this procedure (Table I). This observation confirms the view that the clot-promoting material in the filtered fraction was antihemophilic factor.

Ultracentrifugation of plasma and purified antihemophilic factor. Normal plasma was subjected to ultracentrifugation for $3 \mathrm{hr}$ in gradients of $5-20 \%$ sucrose. Antihemophilic activity was demonstrable in tubes cor- 


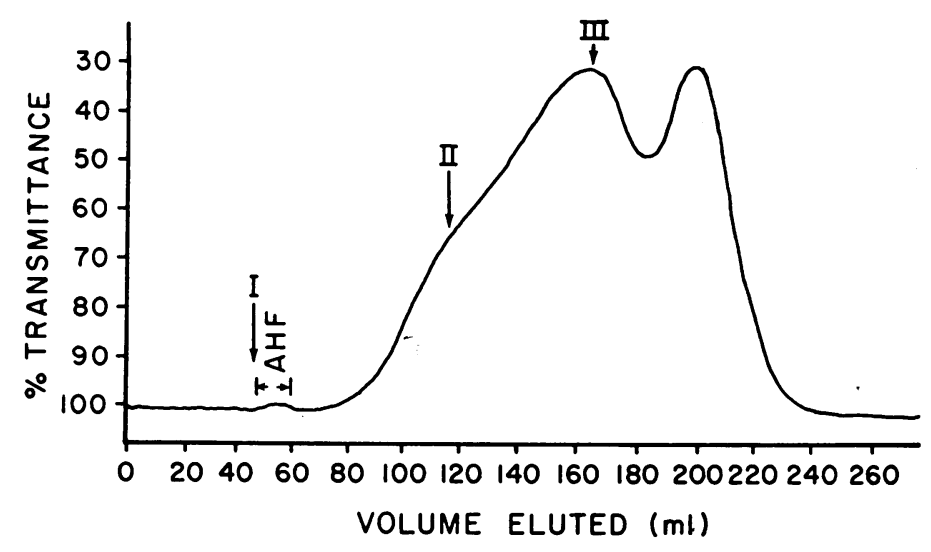

FIGURE 1 Filtration of $5 \mathrm{ml}$ of normal plasma through an agarose column $(2.5 \times 36 \mathrm{~cm})$ at $4^{\circ} \mathrm{C}$. The ordinate records per cent transmittance of light at $280 \mathrm{~m} \mu$, in a Gilford ultraviolet absorbance meter, and is an approximate index of the protein content of the filtered fractions. The abscissa records the milliliter of filtrate collected, beginning at the time the plasma was applied. The peak absorbance obtained by filtration of blue Dextran (I), porcine thyroglobulin (II), and bovine gamma globulin (III) is indicated by vertical arrows, and the portion of the filtrate richest in antihemophilic factor (AHF) by a horizontal double arrow.

responding approximately to the peak optical density of $40 \mathrm{~S}$ subribosomal particles (Fig. 2). As anticipated, the bulk of protein was in those samples from the top of the centrifuge tube. A similar result was obtained by centrifuging a fraction rich in antihemophilic factor, obtained by gel filtration of plasma, but only traces of activity were recovered, apparently because of its instability.

Filtration of hemophilic plasma. Chylomicron-poor plasma was prepared from the venous blood of five patients with classic hemophilia, none related to the other. In each instance, when the plasma was filtered through agarose columns $\left(2.5 \times 36 \mathrm{~cm}\right.$, at $\left.4^{\circ} \mathrm{C}\right)$ a small peak of protein was noted in tubes corresponding to those which would have contained antihemophilic factor, had normal plasma been filtered. The protein content of these peaks ranged from 1.3 to $5 \mu \mathrm{g} / \mathrm{ml}$, averaging $3.5 \mu \mathrm{g} / \mathrm{ml}$. In contrast, the protein content of the tubes with highest specific activity in the 15 experiments with chylomicronpoor normal plasma, filtered at $4^{\circ} \mathrm{C}$, ranged from 1 to $31 \mu \mathrm{g} / \mathrm{ml}$, averaging $8.4 \mu \mathrm{g} / \mathrm{ml}$. Notably, the protein content was $5 \mu \mathrm{g}$ or less in four fractions obtained from normal plasma. Lipid analysis of the tubes of one fasting individual showed the features of fasting normal plasmas, with phospholipids the dominant component and smaller amounts of triglycerides present. In addition, traces of free cholesterol and cholesterol esters were detected. Highly nonpolar compounds were also detectable.

Similar results were obtained by filtering the chylomicron-poor plasma of two unrelated patients who had von Willebrand's disease. The antihemophilic activity of the tube with peak activity was less than $0.01 \mathrm{unit} / \mathrm{ml}$ in one case, and about $0.1 \mathrm{unit} / \mathrm{ml}$ in the other; the protein content was 3 and $4 \mu \mathrm{g} / \mathrm{ml}$, respectively.

Chylomicron-poor plasma of a patient with a circulating anticoagulant directed against antihemophilic fac-

TABLE I

Inactivation of Antihemophilic Factor by a Specific Anticoagulant

\begin{tabular}{lccc}
\hline Mixture* & $\begin{array}{c}\text { Period of } \\
\text { incubation }\end{array}$ & $\begin{array}{c}\text { Clotting } \\
\text { time }\end{array}$ & $\begin{array}{c}\text { Anti- } \\
\text { amophilic } \\
\text { activity }\end{array}$ \\
\hline \multirow{3}{*}{ Fraction + buffer } & min & sec & \% activity \\
& 0 & 105 & 85 \\
& 10 & 102 & 100 \\
Fraction + anticoagulant & 20 & 118 & 60 \\
& 40 & 119 & 45 \\
& 0 & 104 & 90 \\
& 10 & 134 & 15 \\
& 20 & 142 & 9 \\
& 40 & 164 & 3 \\
\hline
\end{tabular}

* $0.6 \mathrm{ml}$ of gel-filtered antihemophilic factor, in barbitalsaline buffer, was incubated at $37^{\circ} \mathrm{C}$ with $0.6 \mathrm{ml}$ of buffer or $0.6 \mathrm{ml}$ of the plasma of a patient with a circulatory anticoagulant, diluted 1:4 with buffer. At intervals, $0.1 \mathrm{ml}$ aliquots were diluted 10-fold with buffer and assayed for antihemophilic activity, and compared with the activity of nonincubated antihemophilic factor, diluted serially with buffer. 


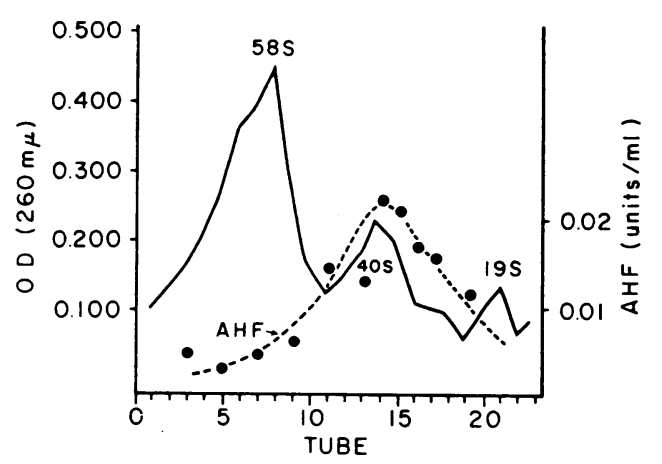

FIgCRE 2 Sucrose gradient ultracentrifugation of $0.2 \mathrm{ml}$ of undiluted normal human plasma and of 19S (porcine thyroglobulin), and $40 \mathrm{~S}$, and $58 \mathrm{~S}$ (subribosomal particles) markers. The left ordinate records the concentration of the markers as a function of absorbance at $260 \mathrm{~m} \mu$. The right ordinate signifies the antihemophilic activity of different fractions of the centrifuged plasma, in units $/ \mathrm{ml}$. The abscissa records the successive samples of the gradient mixture, tube 1 being that at the bottom of the centrifuge tube and tube 23 , that at the top. AHF, antihemophilic factor.

tor was also filtered through agarose. The tube corresponding to that which contained peak antihemophilic activity when normal plasma was filtered through the column was devoid of clot-promoting activity, and contained $5 \mu \mathrm{g}$ of protein $/ \mathrm{ml}$.

Filtration of cryoprecipitates of normal plasma. The gel filtration technique described did not permit purification of large amounts of plasma. In pilot experiments, antihemophilic factor could be separated from cryoprecipitates of normal plasma by gel filtration at $4^{\circ} \mathrm{C}$. In five such experiments, from 12 to $100 \%$ of the antihemophilic factor in the precipitates was recovered, but the best purification achieved, in selected tubes of filtrate, was only $1.3-21$ units $/ \mathrm{mg}$ of protein, averaging 10 units/ mg. No further experiments were performed because it was apparent that the variability was due to the presence at $4^{\circ} \mathrm{C}$ of large amounts of undissolved cryoprecipitate at the top of the columns. Filtration of cryoprecipitates at room temperature was equally disappointingthe recovery was poor.

Stabilization of antihemophilic factor. Gel-filtered antihemophilic factor could be stored after quick-freezing for several days at $-20^{\circ} \mathrm{C}$, but then deteriorated rapidly. More prolonged stability was achieved by the addition of $\frac{1}{5}$ volume of $6 \%$ gelatin. Under these conditions, half of the antihemophilic activity was preserved at $-20^{\circ} \mathrm{C}$ for at least $2 \mathrm{wk}$. About the same stability could be obtained by lyophilization of quick-frozen material containing $1 \%$ gelatin, and storage at $-20^{\circ} \mathrm{C}$. The addition of bovine albumin (at a final concentration of $1 \%$ ), epsilon aminocaproic acid, or glycine (at a final concentration of $0.1 \mathrm{M}$ ), or glycerol (at a final concentration of $50 \%$ ) was much less effective.

\section{DISCUSSION}

Hershgold and his associates (3) reported that antihemophilic activity was present at the void volume when normal plasma was filtered through agarose columns. In agreement with their experiments, antihemophilic activity was found at or near the void volume when normal plasma was filtered through columns of Sepharose 4B. The identity of the antihemophilic factor was determined by the ability of active fractions to correct the defect in hemophilic plasma, and by its destruction by a specific anticoagulant.

The degree of purification achieved by this simple maneuver was exceptional, averaging 3360 -fold in 15 experiments. The specific activity in tubes of greatest purity averaged 67 units/mg of protein; in contrast, normal plasma contains, on the average, 0.014 units $/ \mathrm{mg}$ of protein. About $50 \%$ of total antihemophilic activity could be recovered in a volume of 8-14 $\mathrm{ml}$ after $5 \mathrm{ml}$ of plasma was applied to the column, at a slight loss of purity compared with the tube with greatest activity. These highly purified preparations could be obtained only if the plasma was chylomicron-poor. Lesser purification was achieved from blood obtained at random or after the ingestion of a fatty meal; under these conditions, the fractions filtered at the void volume were turbid as if rich in chylomicrons. Even those specimens prepared from chylomicron-poor plasma contained traces of lipids. No distinct difference was noted between the lipid pattern of tubes rich in antihemophilic factor and the corresponding tubes prepared from the plasma of a hemophiliac; in this comparison, the normal and hemophilic plasmas were chylomicron-poor. No evidence has as yet been found that the lipid in the antihemophilic preparation was anything except a contaminant.

There is every expectation that further purification of antihemophilic factor can be achieved. Small amounts of protein-less, on the average, than that found when normal plasma was filtered-appeared near the void volume upon filtration of plasma from patients with classic hemophilia, von Willebrand's disease. or a circulating anticoagulant directed against antihemophilic factor; the data were insufficient to determine whether the difference between normal and abnormal fractions was significant. Whether this protein represents nonfunctional antihemophilic factor or, as is more likely, contaminating protein is not yet known. The purest antihemophilic factor we obtained was contaminated with appreciable amounts of PTA and traces of Christmas factor and Hageman factor. The nature of the rest of the contaminating protein was not clarified. Conceivably, some fibrinogen may have been present at concentrations below approximately $20 \mu \mathrm{g} / \mathrm{ml}$, the sensitivity of the methods used to detect this protein. How much further remains to be done to obtain antihemophilic factor can 
be judged from earlier studies of Hurt, Wagner, and Brinkhous (9) who precipitated antihemophilic factor from human plasma by adding $\beta$-alanine, and then removed part of contaminating fibrinogen by adsorption with bentonite. Although their products were 5000-fold purified, at least half of the protein in their material was fibrinogen. In agreement with this, Johnson and his associates (2) prepared antihemophilic factor approximately 10,000 -fold purified (164 units/mg of protein) by filtration of a partially purified antihemophilic factor preparation through agarose or by sucrose gradient ultracentrifugation.

In an earlier study, antihemophilic factor, separated by precipitation by concanavalin $\mathrm{A}$, appeared to have a mol wt greater than two million. A similar estimate may be made from data described in the present report, in which antihemophilic activity was excluded from agarose columns and was found in ultracentrifugal fractions corresponding to those containing $40 \mathrm{~S}$ subribosomal particles. The possibility existed that the high molecular weight of our antihemophilic factor was caused by aggregation of smaller units by the cold temperatures to which the plasma was exposed. When antihemophilic factor was separated by gel filtration at $37^{\circ} \mathrm{C}$, however, it appeared at the void volume. Although we cannot exclude the possibility that additional aggregation occurred in the cold, a minimal mol wt of two million remains the best estimate.

Studies of antihemophilic factor have been plagued by the instability of this protein. Lyophilization of purified antihemophilic factor in the presence of $1 \%$ gelatin has provided some degree of stabilization. Since this protein can be injected intravenously, its use may have pragmatic significance.

The question arises whether the technique described in this report can be adapted for clinical use. Conceivably, antihemophilic factor filtered through Sepharose 4B may be toxic. Moreover, to be economically feasible, methods used to purify antihemophilic factor should allow for the use of the rest of plasma. Our attempts to separate antihemophilic factor from cryoprecipitates were marred by erratic recoveries. Preliminary experiments suggest that gel filtration of Cohn fraction I of plasma may pro- vide highly purified antihemophilic factor, and yet allow utilization of the remaining Cohn fractions, ${ }^{1}$ as previously suggested by Johnson (2).

\section{ACKNOWLEDGMENTS}

This study would not have been possible without the expert technical assistance of Miss Barbara Hatch and Mrs. William Zietlow.

This study was supported in part by research grants $\mathrm{HE}$ 01661, HE 05284, and HE 06304 from the National Heart Institute, the National Institutes of Health, U. S. Public Health Service, and in part by a grant from the American Heart Association.

\section{REFERENCES}

1. Kass, L., O. D. Ratnoff, and M. A. Leon. 1969. Studies on the purification of antihemophilic factor (Factor VIII). I. Precipitation of antihemophilic factor by concanavalin A. J. Clin. Invest. 48: 351 .

2. Johnson, A. J., J. Newman, M. B. Howell, and S. Puszkin. 1967. Purification of antihemophilic factor (AHF) for clinical and experimental use. Thromb. Diath. Haemorrh. Suppl. 26.

3. Hershgold, E., L. Silverman, A. Davidson, and M. Janszen. 1967. Native and purified Factor VIII: Molecular and electron microscopical properties and a comparison with hemophilic plasma. Fed. Proc. 26: 488.

4. Pool, J. G., and A. E. Shannon. 1965. Production of high-potency concentrates of antihemophilic globulin in a closed-bag system. N. Engl. J. Med. 273: 1443.

5. Ratnoff, O. D., R. E. Botti, R. T. Breckenridge, and A. S. Littell. 1964. Some problems in the measurement of antihemophilic activity. In The Hemophilias; international symposium. K. M. Brinkhous, editor. University of North Carolina Press, Chapel Hill. 3.

6. Ouchterlony, O. 1964. Gel-diffusion techniques. In Immunological Methods. J. F. Ackroyd, editor. F. A. Davis Company, Philadelphia. 55.

7. Wieme, R. J. 1959. An improved technique of agar-gel electrophoresis on microscope slides. Clin. Chim. Acta. 4: 317.

8. Lowry, O. H., N. J. Rosebrough, A. L. Farr, and R. J. Randall. 1951. Protein measurement with the Folin phenol reagent. J. Biol. Chem. 193: 265.

9. Hurt, J. P., R. H. Wagner, and K. M. Brinkhous. 1966. Five thousandfold purification of human antihemophilic factor. Fed. Proc. 25: 317. (Abstr.)

${ }^{1}$ Zimmerman, T. S., and O. D. Ratnoff. Unpublished observations. 